\title{
Paraventricular porencephalic diverticulum with latent hemiparesis as a complication of ventriculography
}

\author{
RAMON JENKINS \\ From the Washington Hospital Center, Washington, D.C., U.S.A.
}

The development of paraventricular porencephalic diverticula following ventriculography (Fig. 1 and 2) has been described in children suffering from moderate hydrocephalus (Lorber and Grainger, 1963; Grainger and Lorber, 1963; Lorber and Emery, 1964). The present case illustrates such a lesion existing in an apparently normal child some years after ventriculography. It further illustrates that a latent neurological deficit may be made manifest by the action of sedative drugs.

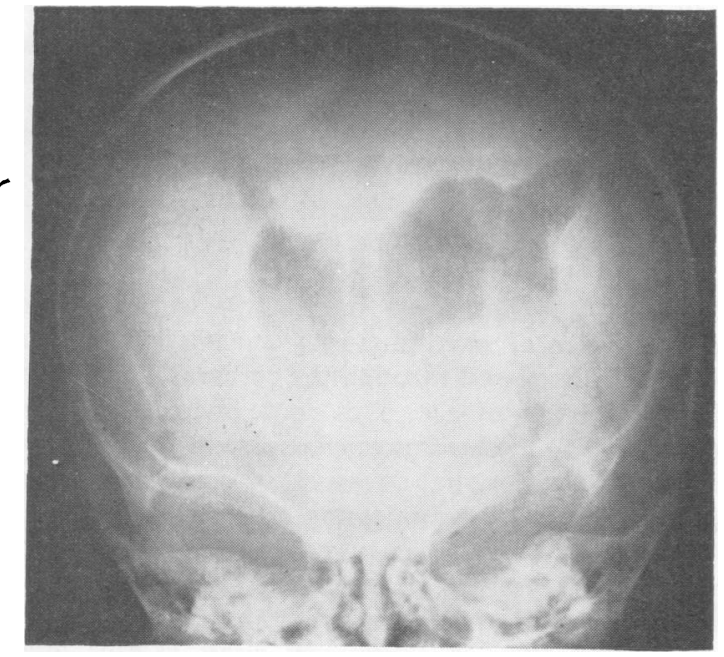

FIG. 1 .

tinued to have occasional fever. On the day of admission he walked normally across the street to his grandparents' house. He spent several hours there and took a short nap. When woken to be taken home he was found to be drowsy and ataxic. The house contained many medicines, including 'heart pills', chlorothiazide, asthma remedies, and tranquillizers, but it was denied that he had had access to these. He became progressively stuporous and was admitted to the hospital.

Significant past history was that the patient had been born in a military hospital where subdural taps and

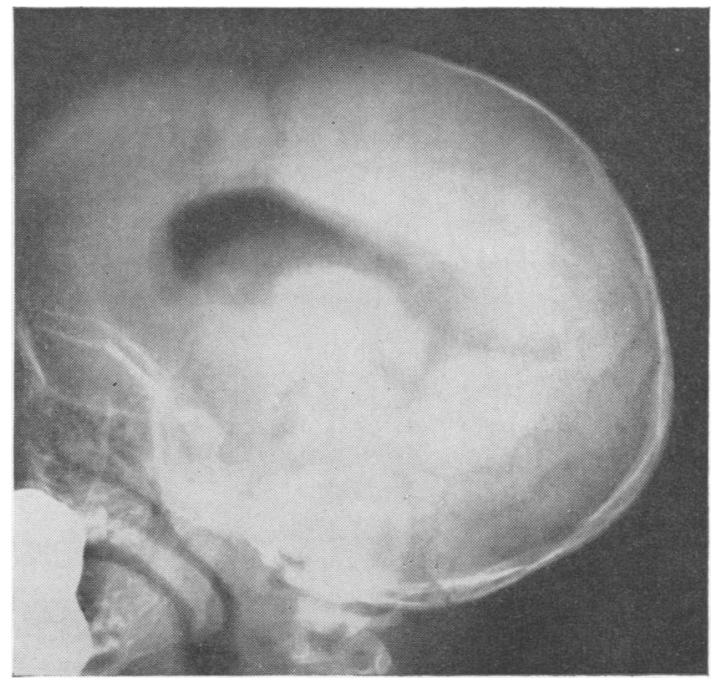

FIG. 2.

FIG. 1. Antero-posterior projection of vertriculogram of a 4-month-old infant with meningomyelocele and mild hydrocephalus, showing paraventricular diverticula in lines of previous needle tracks.

FIG. 2. Lateral projection of patient shown in Figure 1.

CASE REPORT

About four weeks before admission a $3 \frac{1}{2}$-year-old boy began to suffer from a remittent febrile illness. Examination revealed a red throat and post-nasal drip. He received a course of penicillin and improved, but con- ventriculography had been performed at 2 weeks of age. The parents did not know the reason for this, but had been told that no abnormality was found. The patient subsequently passed his milestones of development normally, and before the present illness had been a healthy, active youngster. 


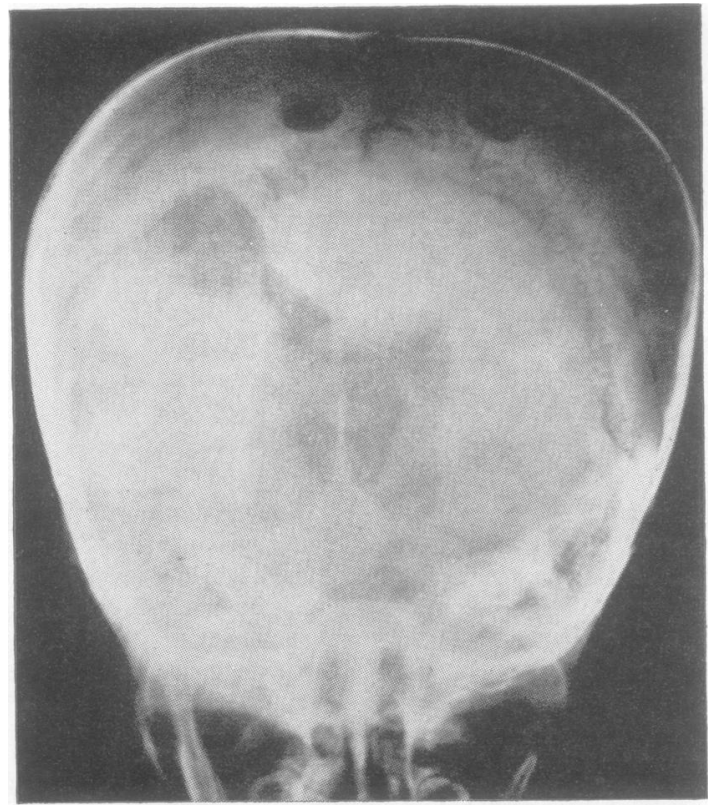

FIG. 3. Antero-posterior half-axial projection of ventriculogram, showing paraventricular diverticulum in line of needle track.

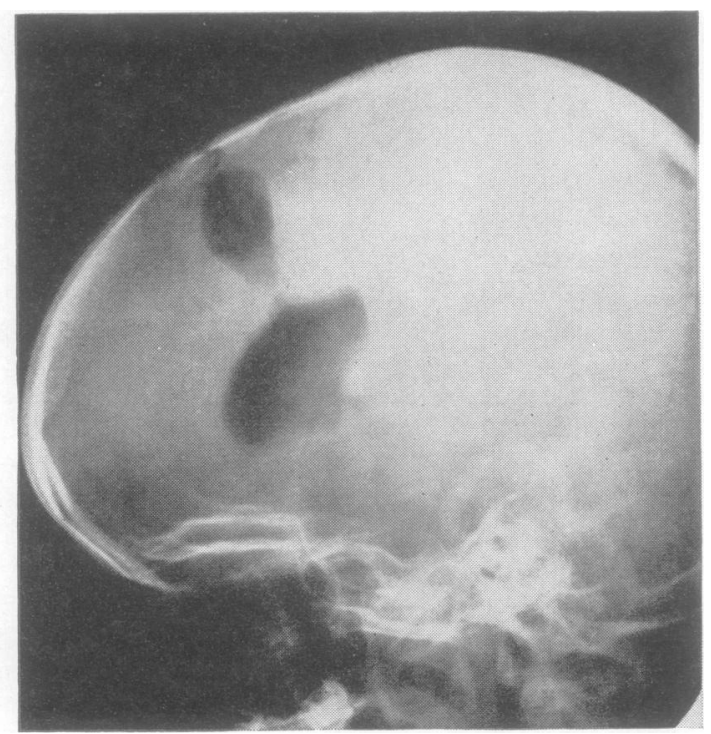

FIG. 4. Lateral projection of ventriculogram, showing paraventricular diverticulum in line of needle track.
PHYSICAL EXAMINATION The patient was a well developed boy who would not obey simple commands but responded to painful stimuli by moving all limbs. More spontaneous movements were present on the right side than on the left side. The presence of a profound degree of left hemiparesis was easily demonstrable by elevating the limbs and releasing them and by applying pressure over the styloid processes. The head was noted to be somewhat box-shaped, with a circumference of $53.0 \mathrm{~cm}$. The optic disks were thought possibly to be slightly blurred.

INVESTIGATIONS A blood barbiturate determination and urinary ferric chloride test were both negative. Lumbar puncture showed the fluid to be under a pressure of $280 \mathrm{~mm}$.; it contained no cells. Ventriculography was performed through posterior parietal burr holes and films of the head in the lateral and frontal projections (Figs. 3 and 4) showed the presence of a porencephalic diverticulum communicating with the right lateral ventricle. Its situation under the coronal suture and the direction of its long axis coincided exactly with that of a previous needle track. It was concluded that this study ruled out a surgically significant lesion and that ingestion of a sedative drug had unmasked a latent left hemiparesis related to the cystic cavity in the right hemisphere.

COURSE The next morning the patient was awake, and is

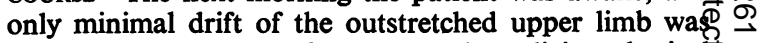
present. By that same afternoon no lateralizing physica感 응 signs could be elicited. A second lumbar puncture showe ${ }^{f}=$ the pressure to be normal. The disks were unchanged but were considered by an ophthalmologist to be a variant of normal. In reply to a direct question, the patient stated he had eaten 'medicine'.

\section{DISCUSSION}

Since it was described by Dandy in 1918, the performance of pneumography by introducing air via a needle passed through the cerebral mantle has become commonplace. This route may be used in preference to the lumbar one because of the presence of raised intracranial pressure, a space-occupying lesion, or non-communicating hydrocephalus. It is favoured in infancy because of the ease and convenience of inserting a needle through the anterior fontanelle and the belief that lumbar pneumoencephalography is excessively risky at this age. Smith and Crothers (1950) reported the occurrence of subdural haematomas following lumbar pneumoencephalography; but correctly placing the needle is difficult in infants, and excessively large quantities of air, of the order of $100 \mathrm{ml}$., had been injected in their patients. With the employment of smaller quantities of air and radiological monitoring with scout films, there is little reason to believe that insertion of air via the lumbar route carries a disproportionate risk after the first few weeks of life.

Complications of ventriculography include extra- 
cerebral and intracerebral bleeding, necrosis of brain tissue around the needle track (Dekaban, 1958), calcification along the needle track (Falk, 1951), the development of sudden cerebral oedema in patients with brain tumours (Fauré and Parienty, 1961), introduction of infection (Hook, 1965), and the development of paraventricular diverticula (loc. cit.).

The present case provides a well documented example of such a diverticulum. It was discovered by chance in an otherwise healthy child and underlines the occurrence of this complication of ventriculography. Previously reported cases occurred among patients suffering from hydrocephalus. The shape of this patient's head and slight dilatation of the ventricles suggest the existence of spontaneously arrested hydrocephalus of mild degree. Lorber and Grainger (1963) considered that diverticula of fusiform shape represent a step towards an eventual dome-shaped filling defect with the base opening into the ventricle. The ventricular surface of the diverticulum in this patient was narrow and showed that such an evolution is not invariable.

Other kinds of diverticula may form spontaneously in hydrocephalic patients; 'pressure diverticula' usually grow downwards through the tentorial incisura to form a cyst in the interpeduncular space, and spontaneous rupture may occur (Dyke, 1942; Pennybacker and Russell, 1943; Torkildsen, 1948). Northfield and Russell (1939) described a different form of diverticulum associated with hemiplegia. It had the appearance of having excavated the cerebral white matter in a creeping manner. Granholm and Rådberg (1965) found diverticula in 'at least four' of 70 hydrocephalic children, but did not mention previous ventriculography.

Latent perceptual or motor deficits may temporarily be made manifest when a patient is under the influence of sedative drugs (Fink, Nathanson, Bergman, and Bender, 1953; Teng and Bender, 1955). This mechanism was clearly operative in the present patient.

\section{SUMMARY}

A paraventricular porencephalic diverticulum, a sequel to ventriculography, was discovered in a healthy $3 \frac{1}{2}$-year-old boy.

A latent motor deficit was temporarily unmasked by ingestion of a sedative drug.

The complications of ventriculography and pneumoencephalography are discussed. With correct techniques it is likely that the lumbar is as safe as the ventricular route for the introduction of air in infants.

I thank Dr. Joseph M. LoPresti, radiologist to the Children's Hospital of the District of Columbia, for providing me with Figures 1 and 2.

\section{REFERENCES}

Dandy, W. E. (1918). Ventriculography following the injection of air into the cerebral ventricles. Ann. Surg., 68, 5-11.

Dekaban, A. S. (1958). Is needle puncture of the brain entirely harmless? Neurology (Minneap.), 8, 556-557.

Dyke, C. G. (1942). Acquired subtentorial pressure diverticulum of a cerebral lateral ventricle. Radiology, 39, 167-174.

Falk, B. (1951). Calcifications in the track of the needle following ventricular puncture. Acta radiol. (Stockh.), 35, 304-308.

Fauré, C., and Parienty, R. (1961). Technique et indications des différentes méthodes d'exploration radiologique de l'encéphale par les contrastes gazeux chez l'enfant. Méd. infant., 68, (no. 7 (Aug. \& Sept.) ) 5-10.

Fink, M., Nathanson, M., Bergman, P. S., and Bender, M. B. (1953). Effect of intravenous barbiturate on perception. Trans. Amer. neurol. Ass., pp. 244-245.

Grainger, R. G., and Lorber, J. (1963). Development of ventricular diverticula following ventricular puncture in hydrocephalic infants. Acta radiol. Diagn. (Stockh.), 1, 569-576.

Granholm, L., and Rådberg, C. (1965). Ventricular diverticulum in infantile hydrocephalus. Ibid., 3, 156-160.

Hook, E. B. (1965). Central nervous system infection in hydrocephalic children following ventriculography. Clin. pediat., 4, 481-483.

Lorber, J., and Grainger, R. G. (1963). Cerebral cavities following ventricular puncture in infants. Clin. Radiol., 14, 98-109.

- , and Emery, J. L. (1964). Intracerebral cysts complicating ventricular needling in hydrocephalic infants: a clinicopathological study. Develop. Med. Child Neurol., 6, 125-139.

Northfield, D. W. C., and Russell, D. S. (1939). False diverticulum of a lateral ventricle causing hemiplegia in chronic internal hydrocephalus. Brain, 62, 311-320.

Pennybacker, J., and Russell, D. S. (1943). Spontaneous ventricular rupture in hydrocephalus, with subtentorial cyst formation. J. Neurol. Psychiat., 6, 38-45.

Smith, H. V., and Crothers, B. (1950). Subdural fluid as a consequence of pneumoencephalography. Pediatrics, 5, 375-389.

Teng, P., and Bender, M. B. (1955). Effect of barbiturates on latent motor deficits. Neurology (Minneap.), 5, 777-786.

Torkildsen, A. (1948). Spontaneous rupture of the cerebral ventricles. J. Neurosurg., 5, 327-339. 